Here we have a young man apparently in good health, without any preliminary signs or symptoms of lead poisoning, suddenly struck down by the most severe of convulsions, which terminate in his death. Has lead a special predilection for the nervous system in certain individuals? If so, are we to regard the convulsions as due to the direct irritation of the lead opon the nervous system, or may we look upon the convulsions, as in the case of uraemia, due to autointoxication from the retention of harmful substances due to defective renal metabolism ?

REFERENCES.

$$
\text { p. } 988 \text {. }
$$

TRYPANOSOMIASIS AND MORBUS DORMITIVA. By ALEX. MAXWELL ADAMS M.B., C.M.Edin., Late of the Gambia Protectorate.

In the British Medicar Journal, March 28th, 1903, there appeared an article of mine entitled Trypanosomiasis and its Cause. In this I asked the question, "Has the trypanosome any relation to sleeping sickness?" pointing out that in Europeans the parasite is found in the peripheral circulation, and suggesting that the African lethargy is an identical disease, and also that the parasite might be found in the brain centres blocking the capillaries, thus causing local anaemia and corresponding somnolence.

This very important contention afterwards received confirmation at the hands of Castellani and Bruce, who first published their results in May and June. 1903, and in the repor of the Royal Society, issued later on, Professor Castellani had first observed a trypanosome in the cerebro-spinal fluid about the end of the year 1902 , but his opinion was that the disease was due to a streptococcus which he had isolated. My paper written in December, 1902, could, therefore, not be influenced by this as yet unpublished observation. I was led to my conclusions by the following clinical considerations:

1. In the trypanosome fever and in sleeping sickness we have the same puffiness of the face and lower eyelids (I was the first I fancy to point out the fugitive nature of the oedema and temporary unilateral distribution).

2. Irritability and apathy in both instances.

3. The same alteration of voice-a characteristic huskiness. I do not here allude to the changes in the speech of the negro where the sounds are unintelligible through paralysis of the tongue, but to a primal change in voice timbre noticed early in the disease, and in all probability due to a local oedema of the larynx. I have not seen this change remarked upon by other observers. The symptoms in the two races seemed to me to differ in degree rather than in kind. The chief difference appeared to be that the European, though apathetic, seemed to have less capacity for sleep than usual, and that the African suffered but slightly from the initial fever.

An important point now arises, Colonel Bruce attributes the infection to a species of tsetse fly, and no doubt in Uganda this holds correct. It is understood that no horse can exist in a country infested with this pest; and it is very interesting to note that in the Gambia (with the exception of Kombo) we have the coexistence of horses and sleeping sickness, the horses in good health, and the sickness quite typical. Therefore, with this $\mathbf{t y}$ presumably absent, what is the origin of the disease in the Gamkia? In my previous article $I$ traced the origin to a rat-bite. However, people are not often so bitten, and cases of the disease in this colony, though somewhat scarce, are not uncommon. Hence I con clude that if the disease were caused by insect bites cases would be numerous, and a state of affairs would exist similar to what we have on the Congo, where we hear of as many as 4,000 cases in one district alone; whereas in the Gambia i is to be doubted if more than a few cases could be collected at one time, facts which point to a different method of dissemination.

In India there is a trypanosome disease in horses probably caused by the common horse fly, and I see little difference between this species (Tabanidae?) and a fly found in the mangrove swamps of the African river. This insect at times attacks the human species and might thus introduce the parasite.

I am more disposed, however, to trace the disease to the rat -in the Senegambia at least. I lean towards this view on account of the long-known and well-proved existence of trypanosomiasis in that animal. Sir Patrick Manson suggests the Ornithodorus moubata as a probable cause, but this animal is unknown in the Gambia, though, judging from analogy, it is quite a possible vehicle of infection, especially when we bear in mind that the parasite of Texan cattle fever is carried by a tick.

Again, the Halteridium of birds has been shown to be one stage of a trypanosome, whose full sexual life is completed in the body of Culex pipiens. As long as the parasite continues its existence by indirect generations or fission, I can easily conceive of several species of blood-sucking insects conveying the fissiparous germs, and that different methods of infection are possible as in typhoid fever.

The real animal in which the complete sexual life of the parasite is reached has not yet been discovered. Till this is done, the tsetse and other flies must be looked upon as an in. direct though no doubt an efficient mode of infection.

The elucidation of the complete cycle of the life-history of the trypanosome is necessary to the complete proof of its relation to sleeping sickness; and when this is done-as I have no doubt it will be-far-reaching practical results will be in sight. My former paper seems to have attracted little attention. In this I put forward my claim to be the first one who suggested that sleeping sickness was caused by a trypanosome, and, secondly (what is more difficult to prove), that the disease in the European and African is identical. Discussions in regard to priority have been rife in regard to this disease. The obserpations contained in my previous paper and this are, I venture to think, non-controversial, and cannot in any way be considered as minimising the splendid work accomplished by Nepveu, Dutton, Castellani, and Bruce.

\section{AN ADDRESS ON THE}

\section{PROPOSED MEDICAL ACTS AMENDMENT BILL.*}

By J. P. WILLIAMS-FREEMAN, M.D.DURH., Chairman of the Division.

Genturmen,-The Committee of the Division which was called to arrange for this meeting suggested that it might tend to expedite the long and somewhat tiresome business before us, if I should, instead of giving a presidential address on some medical or surgical subject, endeavour to analyse and summarize this proposed Bill to Amend the Medical Acts which has been drafted by the Medico-Political Committee of our $\Lambda$ ssociation, and which the Council has sent down for our consideration to-night. In doing so, therefore, I am responsible only for the manner and not for the matter with which I shall try your patience.

There is one central fact which we must never lose sight of in a discussion on this subject, and that is that the Medical Acts of the past and any new legislation which we may hope to get enacted in the future can only befor the benefit of the public, and not for that of the medical profession. No doubt we are quite right to try to bring before Parliament the interests of the profession, and the public would wish to see them safeguarded, but only in so far as those interests are their interests, and not for our professional benefit. They do not wish to work the willing horse to death-they are even anxious to improve the breed of horses-but as only workers for the general weal. The days of special legislation for professional and class interests are happily nearly over.

It may seem unnecessary to insist on this, but I have done so because there is always a natural tendency to forget this principle-not certainly more amongst us than in the ranks of other learned professions-but enough I think to make us often overstate our case and do harm rather than good to our best interests. I doubt, for instance, whether the excited agitation which some of our friends thought fit to indulge in in connexion with the Midwives Bill has done mach to raise the profession in the estimation of the public.

The great central change in the Bill before you is the establishment of one uniform State examination held by the General Medical Council, without passing which no one can practise medicine in the United Kingdom or (subject to any local law) in any part of the empire.

The early parts of the Bill lead up to this examination, and Part VI consists of penal clauses to protect the public from practitioners who have not passed it. It is this penal portion that will perhaps excite most discussion. The public likes and always has liked quacks of all descriptions. A certain interest in the unusual, a vein of superstitious credulity in the mysterious (omne ignotum pro magnifico) which runs * Delivered before the Salisbury Division of the Southern Branch of the British Medical Association. 